\title{
Cardiac tamponade due to Lancefield group A $\beta$ haemolytic streptococcal pericarditis
}

\author{
WT VIGNESWARAN, R HARDIE, J CAMPBELL FERGUSON, A FAICHNEY \\ From Western Infirmary, Glasgow; Heathfield Hospital, Ayr; and Crosshouse Hospital, Kilmarnock
}

Untreated bacterial pericarditis is usually fatal. Pericardial drainage combined with antibiotic treatment has brought the mortality rate down but even now this is around $40 \% .^{\prime 2}$ Purulent pericarditis usually occurs in the setting of major underlying disease and only rarely is the pericardium the primary site of infection. ${ }^{2}$ We report the case of a boy who survived purulent pericarditis caused by a $\beta$ haemolytic streptococcus, Lancefield group A (Streptoccus pyogenes), and who presented with cardiac tamponade.

\section{Case report}

A 14 year old boy was admitted to a district general hospital with a four day history of sore throat, headache, and vomiting. On admission he was flushed with an erythematous rash over his lower abdomen and thighs and a temperature of $37.8^{\circ} \mathrm{C}$. There were no other abnormal findings and his chest radiograph was normal. A throat swab, however, grew Streptococcus pyogenes.

Forty eight hours after admission he complained of retrosternal pain, pleuritic in nature, eased by sitting up. He had a sinus tachycardia of 140 beats/min and a temperature of $38^{\circ} \mathrm{C}$. Over the next 24 hours his condition deteriorated and a repeat chest radiograph showed enlargement of the cardiac shadow (fig 1). Pericardiocentesis was performed and about $5 \mathrm{ml}$ of purulent fluid was aspirated, which showed chains of Gram positive cocci. Subsequently a Lancefield group A $\beta$ haemolytic streptococcus, T/M type $1 / 1$, was isolated. ${ }^{3}$ The patient was transferred to the cardiothoracic unit at the Western Infirmary, Glasgow, for further management after the start of intravenous benzyl penicillin, 4 mega units six hourly.

On arrival the boy was tachypnoeic with an erythematous malar rash and a fading rash on his trunk. There were signs of actue inflammation at the site of a BCG inoculation done two weeks previously. His temperature was $38.5^{\circ} \mathrm{C}$ and he had a sinus tachycardia ( $\left.170 \mathrm{beats} / \mathrm{min}\right)$ with pulsus paradoxus. The neck veins were full and the blood pressure $120 / 90 \mathrm{~mm} \mathrm{Hg}$. Auscultation of the heart revealed soft heart sounds and there was no pericardial

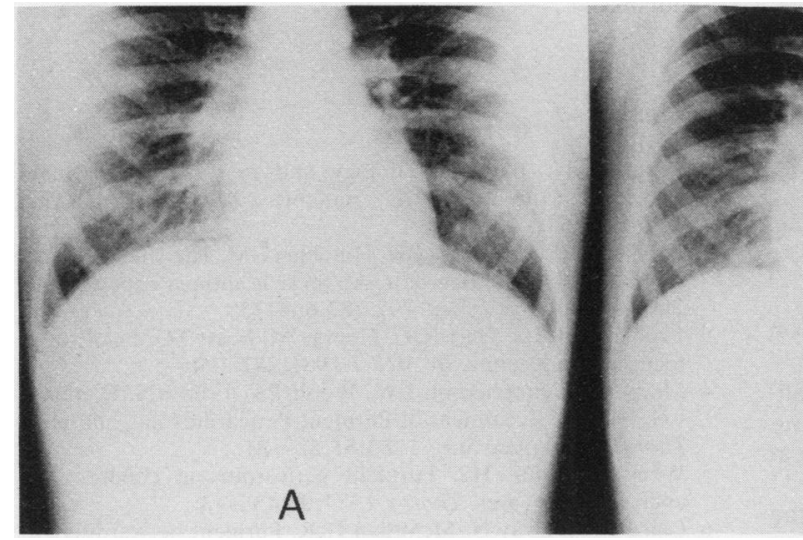

friction. There were basal crepitations in both lungs.

An echocardiogram (fig 2) showed a large pericardial effusion. The white blood cell count on admission was 45 $\times 10^{4} / 1$ with leukaemoid reaction. Pericardiocentesis was carried out with a large bore cannula through the subxiphoid region and $400 \mathrm{ml}$ of purulent fluid were drained. A subsequent echocardiogram showed that most of the

Address for correspondence: Mr WT Vigneswaran, Cardiac Surgery, Ibn Al Bitar Hospital, Salihiyah, Baghdad, Iraq.

Accepted 30 November 1984 pericardial fluid had been removed. Gram stain showed numerous polymorphs and Gram positive cocci; Streptococcus pyogenes of the same type was again isolated and benzyl penicillin, 4 mega units six hourly, was continued. Repeat echocardiography the following day showed reaccumulation of the effusion. This was drained through a left anterolateral thoracotomy by creating a pericardial window. At operation about $500 \mathrm{ml}$ of purulent fluid and a large amount of solid fibrinous exudate were removed. The patient's haemodynamic state improved, with a satisfactory blood pressure and slowing of the heart rate.

Benzyl penicillin was increased to 3 mega units four 


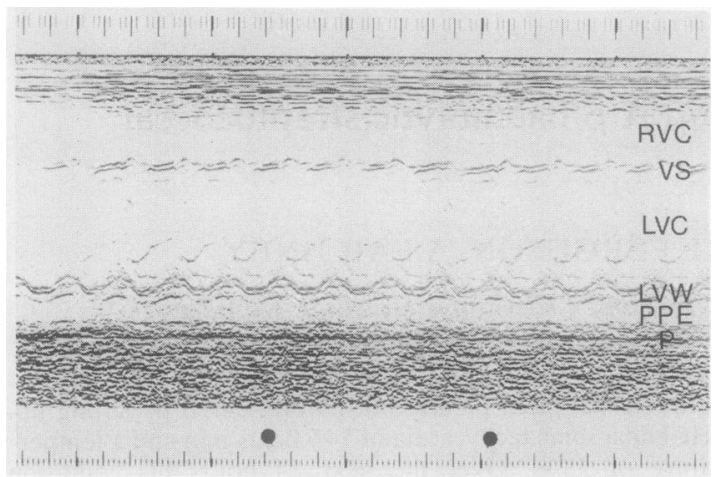

Fig $2 M$ mode echocardiograph before pericardial drainage. $P$-pericardium; PPE-posterior pericardial effusion; $L V W$-left ventricular wall; LVC-left ventricular cavity; VS-ventricular septum; $R V C$ - right ventricular cavity.

hourly on the third postoperative day to give an adequate therapeutic concentration. This was continued for a further seven days and then oral penicillin $\mathrm{V}$ was given for another four weeks. Although he showed improvement, the boy's temperature and white cell count took almost 10 days to return to normal after the pericardiostomy. He developed sloughing of the skin of the soles and palms about the 10th day. His condition was satisfactory for discharge on the 14 th postoperative day and at that time the echocardiogram showed little residual pericardial effusion.

Follow up at eight weeks showed the return of the cardiac shadow in the chest radiograph to normal dimensions; echocardiography showed little pericardial fluid, the white blood count was within normal limits, and the erythrocyte sedimentation rate was down to $35 \mathrm{~mm}$ in one hour. The patient was looking and feeling well and there was no evidence of pericardial constriction.

\section{Discussion}

Purulent pericarditis is commonly associated with infection elsewhere or affects immune compromised patients.' 2 When it causes tamponade it is frequently indistinguishable from other conditions causing cardiac decompensation. It is mandatory to make an early diagnosis and treat patients with pericardial drainage and antibiotics. ${ }^{245}$ Pericardiocentesis can provide adequate drainage if the fluid is thin enough to flow through a needle or percutaneously placed catheter. A pericardiostomy often provides satisfactory drainage. There is a theoretical advantage for pericardiectomy in this condition as cases of late constriction have been reported,${ }^{56}$ but this procedure is believed to be a potential cause of bacteraemia.

Streptococcal pericarditis causing tamponade is rare. In our case the source of infection is uncertain but it may have been the patient's throat or the BCG vaccination site, which showed signs of inflammation. Streptococcus pyogenes was isolated from a throat swab taken soon after admission but unfortunately the organism was not serotyped. T/M type 1/1 strains of Streptococcus pyogenes have been associated with fatal septicaemias in healthy young adults despite appropriate penicillin treatment ${ }^{3}$; there is a suggestion that this particular serotype may be more virulent than others.

An echocardiogram established the diagnosis without doubt and indicated the need for prompt drainage of the purulent material from the pericardial cavity. The failure of the pericardiocentesis before transfer was perhaps due to the small bore needle used and the nature of the mater- $\mathrm{O}$ ial causing the effusion. Subsequent drainage with a large bore cannula relieved the tamponade at first but was not $c$ sufficient to remove all the purulent material. Pericardiostomy was therefore required. This emphasises the need $\overrightarrow{0}$ for early surgical intervention when purulent pericarditis $\infty_{0}$ presents with tamponade.

We thank Dr HJ Dargie and the Department of Bacteriology at the Western Infirmary, Glasgow, for their help in the successful management of this patient. We also wish to thank the Streptococcus Reference Unit, Central Public Health Laboratory, Colindale, London, for serotyping the organism.

\section{References}

1 Feldman W. Bacterial etiology and mortality of purulent pericarditis in paediatric patients. Am J Dis Child 1979; 133:641-4.

2 Klacsmann PG, Bulkley BH, Hutchins GM. The changed spectrum of purulent pericarditis. An 86 year autopsy experience in 200 patients. Am J Med 1977;83:666-73.

3 Cruickshank JG, Hart RJC, George M, Feest TG. Fatal streptococcal septicaemia. Br Med J 1981;282: 1944-5.

4 Morgan RJ, Stephenson LW, Woolf PK, Edie RN, Edmunds LH. Surgical Treatment of Purulent Pericarditis in Children. $J$ Thorac Cardiovasc Surg 1983;85:527-31.

5 Weir EK, Joffe HS. Purulent pericarditis in children. An analysis of 28 cases. Thorax 1977;32:438-43.

6 Caird R, Conway N, McMillan IKR. Purulent pericarditis followed by early constriction in young children. $\mathrm{Br}$ Heart $\mathrm{J}$ 1973;35:201-3. 